\title{
Enhancement of the photoluminescence of a thioamide-based pincer palladium complex in the crystalline state
}

\author{
Junpei Kuwabara, Yasuyuki Ogawa, Ayako Taketoshi, and Takaki Kanbara*
}

Tsukuba Research Center for Interdisciplinary Materials Science (TIMS), Graduate School of Pure and Applied Sciences, University of Tsukuba, 1-1-1 Tennodai, Tsukuba 305-8573, Japan Tel.: +8129-853-5066; Fax: +8129-853-4490; E-mail: kanbara@ims.tsukuba.ac.jp

\section{ABSTRACT}

A thioamide-based pincer $\quad \mathrm{Pd}$ complex,

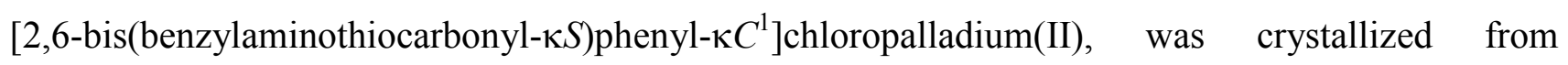
different solvents. The structure of the complex in the solid state depends on hydrogen bonding interactions of cocrystallized solvent molecules with the metal complex in the crystal. The arrangement affects the intensity of the photoluminescence from the crystals. Strong emission was observed from the crystal having a densely-packed arrangement of the complex, whereas the solutions and powders of the complex did not exhibit emission.

Keywords: Pincer complex; Photoluminescence; Hydrogen bonding; Thioamide.

\section{Introduction}

Transition-metal complexes with cyclometalated ligands have attracted great interest because of their emission properties. There are many reports of cyclometalated Pt and Ir complexes with efficient emission and their applications for organic light-emitting diodes (OLEDs) [1]. A cyclometalated pincer ligand having a tridentate coordination ability usually affords better thermal stability to complexes than a bidentate ligand. We recently reported pincer complexes with thioamide groups and their emitting properties [2]. The Pt complex having the thioamide-based pincer ligand exhibits stronger emission than the corresponding Pd complex, which is usual phenomena owing to facile a nonradiative decay pathway via molecular distortion 
in the case of a Pd complex [1c,3]. The fabrication of hybrid films of the pincer Pd complex bearing secondary thioamide units and polyvinylpyrrolidone leads to improvement of its emission compared to the original emission of the $\mathrm{Pd}$ complex in the solid state at room temperature [4]. Since polyvinylpyrrolidone is much more effective than polystyrene, one can assume that reason for the enhancement of emission is hydrogen bonding between the N-H moiety in the secondary thioamide group and a pyrrolidone unit in the polymer. Hydrogen-bonding interactions between $\mathrm{Cl}^{-}$and the Pt complex having the same ligand increase the photoluminescence in solution [2d]. The solid state of complexes can be an ideal way to evaluate the effect of hydrogen bonding on emission, because the hydrogen bonding and the molecular arrangement of the complex can be determined by single crystal X-ray diffraction analysis. Emission from the solid state is usually weak owing to concentration-dependent quenching processes [5]. However, some compounds exhibit strong emissions in the solid state compared to the solution state which is known as aggregation-induced emission [6-8]. Here we report the relationship between photoluminescence of the thioamide-based pincer Pd complex and its molecular arrangement containing hydrogen bonds in the crystalline state. Some of crystals exhibit stronger photoluminescence than that in dilute solutions at room temperature.

\section{Results and discussion}

2.1. Molecular arrangement of Pd complex 1 in different crystals

The thioamide-based pincer Pd complex, [2,6-bis(benzylaminothiocarbonyl- $\kappa S$ )phenyl- $\left.\kappa C^{1}\right]$ chloropalladium(II), 1 was prepared according to the literature methods [4].

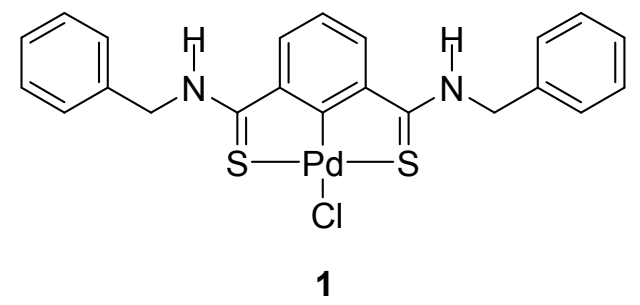

The complex 1 has two secondary thioamide groups acting as hydrogen-bonding donors and a $\mathrm{Cl}$ ligand acting as a hydrogen-bonding acceptor. The complex is only soluble in polar organic 
solvents such as dimethylformamide (DMF), $N$-methylpyrrolidone (NMP), dimethylacetamide (DMAc), and dimethylsulfoxide (DMSO) presumably due to a formation of a hydrogen-bonding network. Since the polar solvents interact with the secondary thioamide moieties, the interaction may change the hydrogen-bonding network. To evaluate the supramolecular interactions, complex 1 was crystallized from four kinds of solvents such as DMF, NMP [4], DMAc, and DMSO acting as a hydrogen-bonding acceptors. The crystal structures of the different solvates reveal the molecular arrangement and hydrogen-bonding interactions of these groups with the solvent molecules (Fig. 1). The crystallization of complex 1 from a solution in DMF yielded two types of crystals. Fig. 1a shows one of the crystal structures containing a DMF molecule. One of the thioamide groups has a hydrogen bond to the oxygen atom in the DMF molecule. The other thioamide group has hydrogen-bonding interaction to the $\mathrm{Cl}$ ligand in an adjacent complex. Similar hydrogen bonding networks of the pincer complexes have been reported in literature [9]. The $\mathrm{N}-\mathrm{H} \cdots \mathrm{Cl}$ interaction forms a linear arrangement of $\mathbf{1}$, hence termed $\mathbf{1} \cdot \mathbf{D} \mathbf{M F}_{\mathbf{L}}$. The distance between hydrogen-bonding donors and acceptors are within the usual range (Table 1) [10]. The other crystal of 1 obtained from a solution in DMF also has one DMF molecule interacting with a thioamide group (Fig. 1b). The difference between two crystals is the molecular arrangement formed by hydrogen-bonding network. Fig. 1b shows that the Pd complexes are connected by $\mathrm{N}-\mathrm{H} \cdots \mathrm{Cl}$ hydrogen bonds in a zigzag manner, hence termed $\mathbf{1} \cdot \mathbf{D} \mathbf{M F}_{\mathbf{Z}}$. The angle of Pd-Cl1-H2 is 91.5 degrees. Since the shortest Pd-Pd distances in crystal lattice of $\mathbf{1} \cdot \mathbf{D} \mathbf{M F}_{\mathbf{L}}$ and $\mathbf{1} \cdot \mathbf{D} \mathbf{M F}_{\mathbf{Z}}$ are $7.932 \AA$ and $7.492 \AA$, respectively, there are no $\mathrm{d}^{8}-\mathrm{d}^{8}$ metal-metal interactions which induces aggregation-induced emission as found in some other cases [7]. The crystal with a NMP molecule, 1·NMP, has a linear molecular arrangement similar to $\mathbf{1} \cdot \mathbf{D} \mathbf{M F}_{\mathbf{L}}$ (Fig. 1c). On the other hand, a crystal of $\mathbf{1}$ obtained with a DMAc molecule, 1·DMAc, has a zigzag arrangement which is quite similar to $\mathbf{1} \cdot \mathbf{D M F}$ (Fig. 1d). Crystallization from DMSO gave a crystal having two DMSO molecules per one Pd complex, which is different from the above-mentioned crystals possessing one solvent molecule. The crystal structure of 1-2DMSO shows that both of the thioamide groups interact with DMSO molecules and not with the $\mathrm{Cl}$ ligand in the adjacent complex (Fig. 1e). The molecule has a crystallographic mirror plane containing $\mathrm{Pd}$ and $\mathrm{Cl}$ atoms. The Pd-Pd distance in the crystal lattice is $5.651 \AA$ which is too long for a $\mathrm{d}^{8}-\mathrm{d}^{8}$ metal-metal 
interaction. However, the two Pd complexes are located close to each other in comparison with the arrangement in the other crystals. The distance between the Pd center and the nitrogen atom in the closest complex is $3.702 \AA$.

Insert Fig. 1

Insert Table 1

$\mathrm{Cl}$ ligands in a late-transition-metal complex are usually strong hydrogen-bonding acceptors [11]. Since the N-H groups are hydrogen-bonded to DMSO molecules in 1.2DMSO, there are no interactions between the $\mathrm{Cl}$ ligand and the $\mathrm{N}-\mathrm{H}$ groups. However, the $\mathrm{Cl}$ ligand does interact with the $\mathrm{C}-\mathrm{H}$ group at the para position of the cyclometalating benzene ring (Fig. 2). This interaction forms a linear chain-like arrangement along the $b$ axis in an orthorhombic lattice. Therefore, the angle of $\mathrm{C}-\mathrm{H} \cdots \mathrm{Cl}$ is $180^{\circ}$ which is ideal for a hydrogen-bonding interaction [10]. The distance between $\mathrm{C}-\mathrm{H} \cdots \mathrm{Cl}-\mathrm{Pd}$ is $2.571 \AA$ which is shorter than the sum of the van der Waals radii for $\mathrm{H}$ and $\mathrm{Cl}(2.95 \AA)$. Since the examples of a hydrogen bond of a C-H group are very rare compared to classical hydrogen bond of N-H and O-H groups [12], the clear evidence for the hydrogen bond of $\mathrm{C}-\mathrm{H} \cdots \mathrm{Cl}-\mathrm{Pd}$ is notable.

Insert Fig. 2

\subsection{Photoluminescence of $P d$ complex 1 in the crystalline state.}

Pd complex 1 exhibits green emission in $\mathrm{CH}_{2} \mathrm{Cl}_{2} / \mathrm{THF}(3: 2$, v/v) glass matrix at $77 \mathrm{~K}$, whose quantum yield is $65 \%$. On the other hand, no emission was observed from the solution of 1 at room temperature. The photoluminescence of the five kinds of crystals were elucidated by the visual observation as a preliminary evaluation. Fig. 3 shows the photographs of the crystals under UV light at the wavelength of $254 \mathrm{~nm}$ at room temperature. Although the solution of complex $\mathbf{1}$ does not exhibit emission, the crystals of $\mathbf{1} \cdot \mathbf{D M F}_{\mathbf{L}}, \mathbf{1} \cdot \mathbf{N M P}$, and $\mathbf{1 \cdot 2 D M S O}$ exhibits greenish yellow emission upon excitation, with quantum yields of $1.43,2.11$, and $4.88 \%$, respectively. Since the quantum yields of $\mathbf{1}$ in the powder state is less than $0.1 \%$ at room temperature, the 
quantum yields of $\mathbf{1}$ are improved by the crystallization process. On the other hand, $\mathbf{1} \cdot \mathbf{D} \mathbf{M F}_{\mathbf{Z}}$ and 1-DMAc exhibits negligible emission as shown in Fig. $3 \mathrm{~b}$ and $3 \mathrm{~d}$, respectively. The quantum yields of the crystals are less than $0.1 \%$. Consequently, an aggregation-induced emission was observed in particular crystals such as $\mathbf{1} \cdot \mathbf{D M F}_{\mathrm{L}}, \mathbf{1} \cdot \mathbf{N M P}$, and $\mathbf{1 \cdot 2 D M S O}$.

Insert Fig. 3

Fig. 4 shows the emission spectra of $\mathbf{1} \cdot \mathbf{D M F}_{\mathbf{L}}, \mathbf{1} \cdot \mathbf{N M P}$, and $\mathbf{1 \cdot 2 D M S O}$ as well as spectrum of $\mathbf{1}$ in a frozen matrix of $\mathrm{CH}_{2} \mathrm{Cl}_{2} / \mathrm{THF}$ at $77 \mathrm{~K}$. The emission from crystals appears at longer wavelength than that of solutions. The spectra of $\mathbf{1} \cdot \mathbf{D} \mathbf{M F}_{\mathbf{L}}$ and $\mathbf{1} \cdot \mathbf{N M P}$ are very similar to each other. However, the spectrum of $\mathbf{1 \cdot 2 D M S O}$ is different from those of $\mathbf{1} \cdot \mathbf{D} \mathbf{M F}_{\mathbf{L}}$ and $\mathbf{1} \cdot \mathbf{N M P}$. The absorption spectrum of complex 1 in DMF exhibits the maximum absorption at $374 \mathrm{~nm}$ and shoulder peak at around $430 \mathrm{~nm}$ (See Supporting Information, Fig. S-1). The spectrum in DMSO exhibits a similar absorption curve. On the bases of a DFT calculation of a thioamide-based pincer Pd complex, the absorptions in the long-wavelength region can be assigned as metal-to-ligand charge transfers (MLCT) [2e]. The excitation spectra of $\mathbf{1} \cdot \mathbf{D M F}_{\mathbf{L}}, \mathbf{1} \cdot \mathbf{N M P}$, 1.2DMSO, and 1 in a frozen matrix of $\mathrm{CH}_{2} \mathrm{Cl}_{2} / \mathrm{THF}$ at $77 \mathrm{~K}$ were measured for a comparison of three different conditions (Fig. S-2). The excitation spectra show two maximum peaks at around $375 \mathrm{~nm}$ and $430 \mathrm{~nm}$. These peaks correspond to the maximum absorption and a shoulder peak in the absorption spectrum in the solution state at room temperature. These results indicate no special photoexcitation such as metal-metal-to-ligand charge transfer in the solid state and glass matrix state. The origin of the emission is likely to be MLCT both in the solid state and in the frozen matrix based on the DFT calculation and the spectroscopic data.

Insert Fig. 4

\subsection{Relationship of Crystal Structure and Photoluminescence of Pd complex 1}

The emissive crystals, $\mathbf{1} \cdot \mathbf{D} \mathbf{M F}_{\mathbf{L}}$ and $\mathbf{1} \cdot \mathbf{N M P}$, have similar linear molecular arrangements in the solid state (Fig. 1a and 1c). The non-emissive crystals, $\mathbf{1} \cdot \mathbf{D} \mathbf{M F} \mathbf{Z}$ and $\mathbf{1} \cdot \mathbf{D M A c}$, have the common 
zigzag arrangement (Fig. $1 \mathrm{~b}$ and $1 \mathrm{~d}$ ). In addition, the crystal of 1.2DMSO having unique arrangement exhibits emission at different wavelength from other crystals (Fig. 1e). These phenomena strongly indicate that the molecular arrangement in the crystals affects the intensity and wavelength of emission. In general, the origin of aggregation-induced emission of a metal complex is an intermolecular metal-metal interaction [7]. However, no intermolecular interactions between $\mathrm{Pd}$ centers were observed in crystallographic results and spectroscopic measurements reported herein. From the many of crystallographic data, we focus on the density of the crystals (Table 2). The density of the crystal bearing the linear molecular arrangement is $1.583 \mathrm{~g} \mathrm{~cm}^{-3}\left(\mathbf{1} \cdot \mathbf{D M F}_{\mathbf{L}}\right)$ and $1.591 \mathrm{~g} \mathrm{~cm}^{-3}(\mathbf{1} \cdot \mathbf{N M P})$ which are significantly higher than that of the zigzag arrangement, $1.564 \mathrm{~g} \mathrm{~cm}^{-3}\left(\mathbf{1} \cdot \mathbf{D} \mathbf{M F}_{\mathbf{Z}}\right)$ and $1.537 \mathrm{~g} \mathrm{~cm}^{-3}(\mathbf{1} \cdot \mathbf{D M A c})$. The high density probably prevents the distortion of the complex at the exited state resulting in suppression of nonradiative decay pathway via molecular distortion. Therefore, densely-packed crystals with hydrogen bonds exhibit emission at room temperature. In terms of 1.2DMSO, the density of the crystal is $1.571 \mathrm{~g} \mathrm{~cm}^{-3}$ which is relatively high compared with the crystals with no emission. In addition, partial stacking of the Pd complex is observed in the crystal lattice. These may be the reason for relatively strong emission and different emission wavelength from $\mathbf{1} \cdot \mathbf{D M F}_{\mathbf{L}}$ and 1•NMP.

\section{Conclusions}

Five kinds of crystal structures of complex 1 with a different hydrogen bonding interactions were revealed by single-crystal X-ray diffraction analyses. The molecular arrangements of the crystals are divided into three groups which are linear, zigzag, and stacking arrangements. The zigzag arrangement is unfavorable for emission because of loose packing of the Pd complex in the crystal. The crystals having high density exhibit aggregation-induced emission. This work reveals that a molecular arrangement, which is induced by hydrogen bonding, can be important for emission in the solid state at room temperature. This result will provide a guide for maximizing the potential for emission by complexes in the solid state.

\section{Experimental}




\subsection{General}

The IR spectra were measured with JASCO FT/IR-300 spectrophotometer. The UV/Vis absorption spectra were measured with JASCO V-630 spectrophotometer. To measure the PL characteristics of the complexes in the solution and the glass-matrix state, the dissolved oxygen in the solution was removed by bubbling with $\mathrm{N}_{2}$ for $20 \mathrm{~min}$. The emission spectra at room temperature were measured with a JASCO FP-6200 spectrophotometer. The emission spectra at $77 \mathrm{~K}$ were measured with a Hitachi F-4010 spectrophotometer using deaerated $\mathrm{CH}_{2} \mathrm{Cl}_{2} / \mathrm{THF}(3: 2$, $\mathrm{v} / \mathrm{v}$ ) as glass matrix. The quantum yields at room temperature were measured by an absolute PL quantum yield measurement system (C9920-02, Hamamatsu photonics k.k.). The quantum yields at $77 \mathrm{~K}$ were measured by the same equipment using deaerated $\mathrm{CH}_{2} \mathrm{Cl}_{2} / \mathrm{THF}(3: 2, \mathrm{v} / \mathrm{v})$ as glass matrix. The Pd complex 1 was prepared according to the literature method [4].

\subsection{X-ray crystal structure determination}

Single crystals were obtained from the concentrated solution of complex $\mathbf{1}$ in the corresponding solvent. The crystal structure of 1·NMP have been reported in the previous literature [4]. Crystals were mounted on a glass capillary tube. Intensity data were collected on a Rigaku R-AXIS Rapid diffractometer with Mo $K \alpha$ radiation. Crystallographic data and details of refinement of the complexes are summarized in Table 2. A full matrix least-squares refinement was used for non-hydrogen atoms except for disordered atoms with anisotropic thermal parameters method by SHELXL-97 program. Hydrogen atoms except for $\mathrm{N}-\mathrm{H}$ group in $\mathbf{1} \cdot \mathbf{D M F}_{\mathbf{L}}, \mathbf{1} \cdot \mathbf{D} \mathbf{M F}_{\mathbf{Z}}$, and 1-2DMSO were placed at the calculated positions and were included in the structure calculation without further refinement of the parameters. CCDC 794884, 794885, 750102, 794883 and 794887 contains the supplementary crystallographic data for $\mathbf{1} \cdot \mathbf{D} \mathbf{M F} \mathbf{L}, \mathbf{1} \cdot \mathbf{D} \mathbf{M F} \mathbf{Z}, \mathbf{1} \cdot \mathbf{N M P}$, 1.DMAc, and 1.2DMSO, respectively. These data can be obtained free of charge via http://www.ccdc.cam.ac.uk/conts/retrieving.html, or from the Cambridge Crystallographic Data Centre, 12 Union Road, Cambridge CB2 1EZ, UK; fax: (+44) 1223-336-033; or e-mail: deposit@ccdc.cam.ac.uk. 


\section{Acknowledgements}

The authors thank to the Chemical Analysis Center of University of Tsukuba for the measurements of X-ray analysis. Prof. T. Nabeshima and Dr. M. Yamamura are grateful for the support of quantum yield measurements. J.K. acknowledges the Kurata Memorial Hitach Science and Technology Foundation for financial support.

\section{References}

[1] (a) Y. Chi, P.-T. Chou, Chem. Soc. Rev. 39 (2010) 638-655; (b) J.A.G. Williams, Top. Curr. Chem. 281 (2007) 205-268; (c) R.C. Evans, P. Douglas, C.J. Winscom, Coord. Chem. Rev. 250 (2006) 2093-2126; (d) S.J. Farley, D.L. Rochester, A.L. Thompson, J.A.K. Howard and J.A.G. Williams, Inorg. Chem. 44 (2005) 9690-9703.

[2] (a) T. Kanbara, K. Okada, T. Yamamoto, H. Ogawa, T. Inoue, J. Organomet. Chem. 689 (2004) 1860-1864; (b) M. Akaiwa, T. Kanbara, H. Fukumoto, T. Yamamoto, J. Organomet. Chem. 690 (2005) 4192-4196; (c) K. Okamoto, T. Kanbara, T. Yamamoto, A. Wada, Organometallics 25 (2006) 4026-4029; (d) K. Okamoto, T. Yamamoto, M. Akita, A. Wada, T. Kanbara, Organometallics 28 (2009) 3307-3310; (e) J. Kuwabara, G. Munezawa, K. Okamoto, T. Kanbara, Danlton Trans. 39 (2010) 6255. (f) J. Kuwabara, T. Kanbara, J. Photopolym. Sci. Technol. 21 (2008) 349-353.

[3] Examples of emissive Pd complexes at room temperature (a) F. Neve, A. Crispini, C.D. Pietro, S. Campagna, Organometallics 21 (2002) 3511-3518; (b) T. Tsubomura, Y. Ito, S. Inoue, Y. Tanaka, K. Matsumoto, T. Tsukuda, Inorg. Chem. 47 (2008) 481-486.

[4] Y. Ogawa, A. Taketoshi, J. Kuwabara, K. Okamoto, T. Fukuda, T. Kanbara, Chem. Lett. 39 (2010) 385-387.

[5] B. Ma, P.I. Djurovich, M.E. Thompson, Coord. Chem. Rev. 249 (2005) 1501-1510.

[6] Y. Hong, J.W.Y. Lam, B.Z. Tang, Chem. Commun. (2009) 4332-4353.

[7] (a) V.W.-W. Yam, K.M.-C. Wong, N. Zhu, J. Am. Chem. Soc. 124 (2002) 6506-6507; (b) V.W.-W. Yam, K.H.-Y. Chan, K.M.-C. Wong, N. Zhu, Chem. Eur. J. 11 (2005) 4535-4543; (c) 
Y. Sun, K. Ye, H. Zhang, J. Zhang, L. Zhao, B. Li, G. Yang, B. Yang, Y. Wang, S.-W. Lai, C.-M. Che, Angew. Chem. Int. Ed. 45 (2006) 5610-5613; (d) K. Umakoshi, T. Kojima, K. Saito, S. Akatsu, M. Onishi, S. Ishizaka, N. Kitamura, Y. Nakao, S. Sakaki, Y. Ozawa, Inorg. Chem. 47 (2008) 5033-5035; (e) T. Abe, T. Itakura, N. Ikeda, K. Shinozaki, Dalton Trans. (2009) 711-715. [8] (a) Q. Zhao, L. Li, F. Li, M. Yu, Z. Liu, T. Yi, C. Huang, Chem. Commun. (2008) 685-687; (b) Y. You, H.S. Huh, K.S. Kim, S.W. Lee, D. Kim, S.Y. Park, Chem. Commun. (2008) 3998-4000; (c) K. Huang, H. Wu, M. Shi, F. Li, T. Yi, C. Huang, Chem. Commun. (2009) 1243-1245.

[9] (a) K. Okamoto, T. Yamamoto, T. Kanbara, J. Nanosci. Nanotechnol. 9 (2009) 646-649. (b) P.J. Davies, N. Veldman, D.M. Grove, A.L. Spek, B.T.G. Lutz, G. van Koten, Angew. Chem. Int. Ed. Engl. 35 (1996) 1959-1961; (c) M. Albrecht, M. Lutz, A. L. Spek, G. van Koten, Nature 406 (2000) 970-974; (d) M. Albrecht, M. Lutz, A.M.M. Schreurs, E.T.H. Lutz, A.L. Spek, G. van Koten, J. Chem. Soc., Dalton Trans. (2000) 3797-3804.

[10] (a) M.D. Joesten, L.J. Schaad, Hydrogen Bonding, Marcel Dekker Inc., New York, 1974; (b) G.R. Desiraju, T. Steiner, The Weak Hydrogen Bond, Oxford University press Inc., New York, 1999.

[11] G. Aullón, D. Bellamy, L. Brammer, E.A. Bruton, A.G. Orpen, Chem. Commun. (1998) 653-654.

[12] (a) Y. Hua, A.H. Flood, Chem. Soc. Rev. 39 (2010) 1262-1271; (b) L. Pedzisa, B.P. Hay, J. Org. Chem. 74 (2009) 2554-2560. 

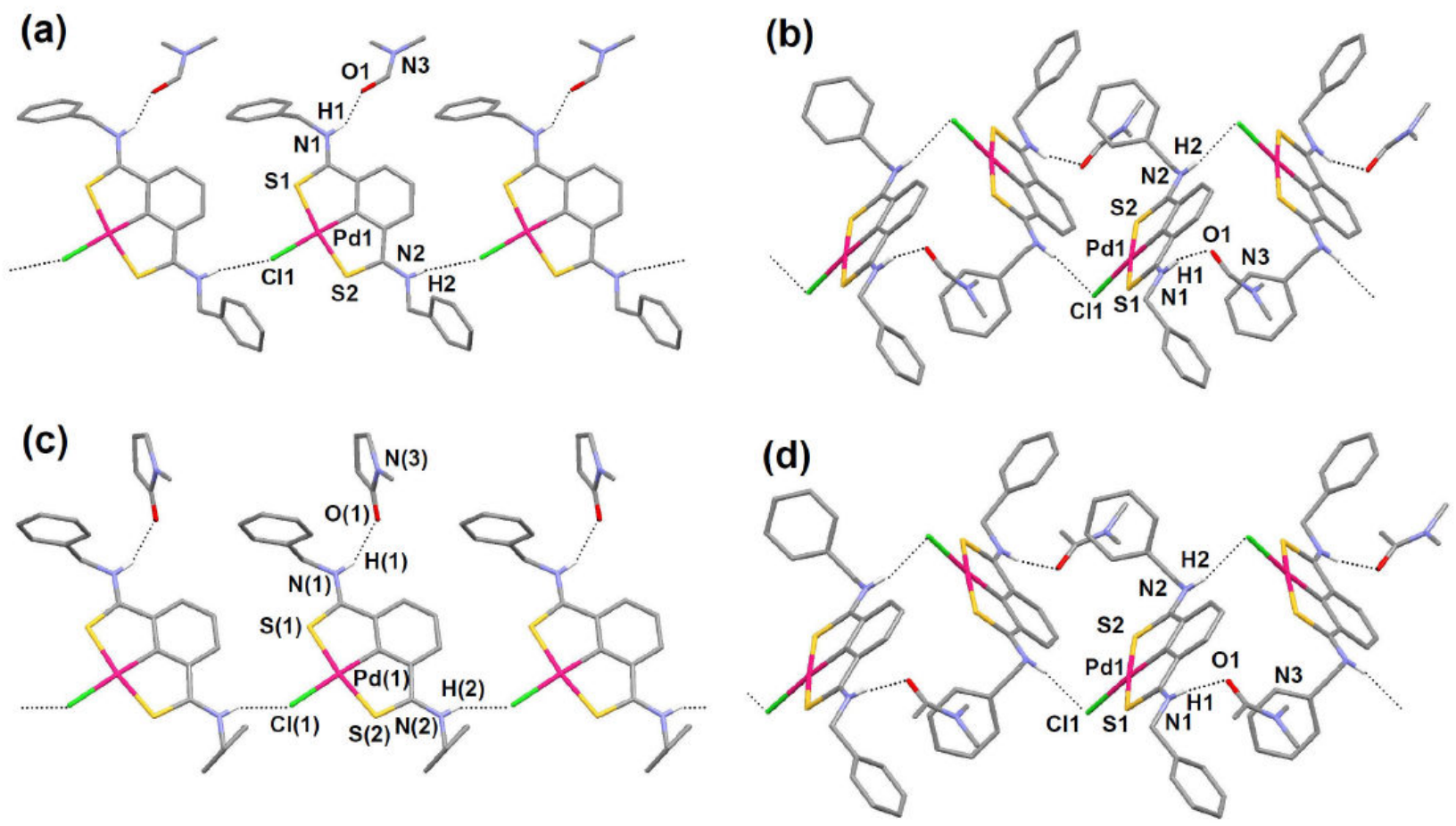

(e)

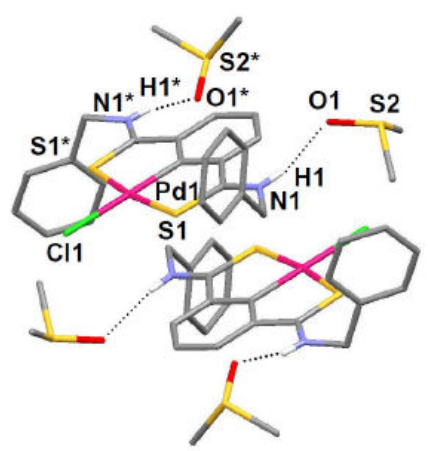

Fig. 1. Packing diagrams for (a) $\mathbf{1} \cdot \mathbf{D M F}_{\mathbf{L}}$, (b) $\mathbf{1} \cdot \mathbf{D M F}_{\mathbf{Z}}$, (c) $\mathbf{1} \cdot \mathbf{N M P}$, (d) 1·DMAc, and (e) 1·2DMSO. Hydrogen atoms except for $\mathrm{N}-\mathrm{H}$ are omitted for clarity. Labeling and coloring schemes are as follows: Pd (magenta); S (yellow); N (purple); Cl (lime green); C (gray); O (red); H (white). 


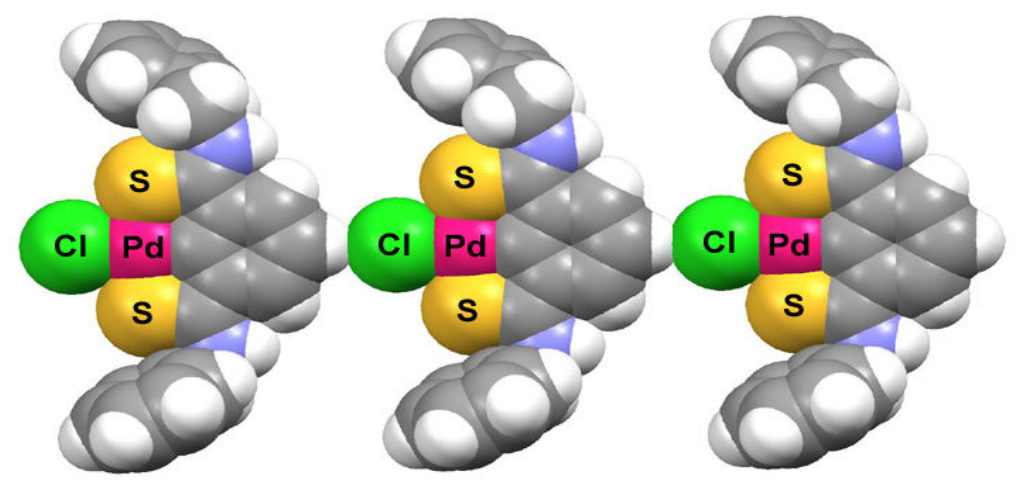

Fig. 2. Space filling model of 1-2DMSO indicating hydrogen bonding between $\mathrm{C}-\mathrm{H} \cdots \mathrm{Cl}-\mathrm{Pd}$. The DMSO molecules are omitted for clarity. Labeling and coloring schemes are as follows: Pd (magenta); S (yellow); N (purple); Cl (lime green); C (gray); H(white). 


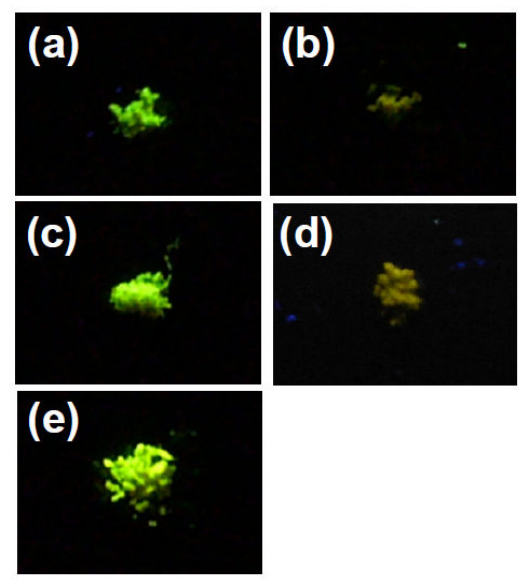

Fig. 3. Photographs of (a) $1 \cdot \mathbf{D M F}_{\mathbf{L}}$, (b) $\mathbf{1} \cdot \mathbf{D} \mathbf{M F}_{\mathbf{Z}}$, (c) $\mathbf{1} \cdot \mathbf{N M P}$, (d) $\mathbf{1} \cdot \mathbf{D M A c}$, and (e) $\mathbf{1 \cdot 2 D M S O}$ under UV light at the wavelength of $254 \mathrm{~nm}$. 


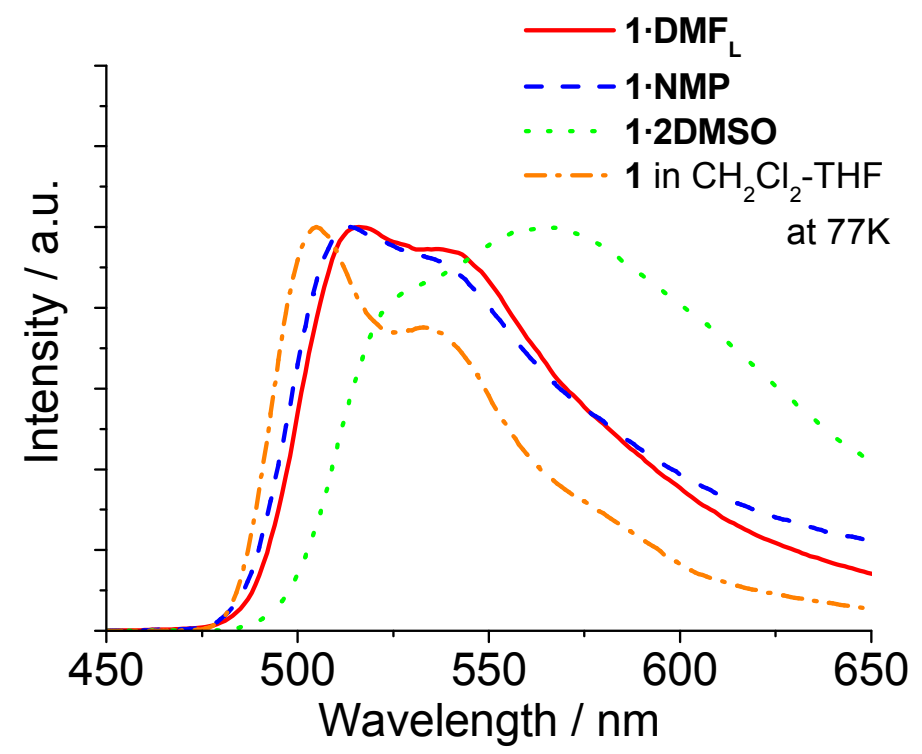

Fig. 4. Emission spectra of $\mathbf{1} \cdot \mathbf{D M F}_{\mathbf{L}}, \mathbf{1} \cdot \mathbf{N M P}, \mathbf{1} \cdot \mathbf{2 D M S O}\left(\lambda_{\mathrm{ex}}=374 \mathrm{~nm}\right)$ and $\mathbf{1}$ in a frozen matrix of $\mathrm{CH}_{2} \mathrm{Cl}_{2} / \mathrm{THF}(3: 2)$ at $77 \mathrm{~K}\left(\lambda_{\mathrm{ex}}=384 \mathrm{~nm}\right)$. 
Table 1

Selected Bond Distance $(\AA)$, Angle (deg) and Distance of Hydrogen Bonds $(\AA)$

\begin{tabular}{|c|c|c|c|c|c|}
\hline & $1 \cdot \mathrm{DMF}_{\mathrm{L}}$ & $1 \cdot \mathrm{DMF}_{\mathrm{Z}}$ & $1 \cdot \mathrm{NMP}^{\mathrm{a}}$ & 1.DMAc & 1.2DMSO \\
\hline $\mathrm{M}-\mathrm{C} 1$ & $1.962(2)$ & $1.960(3)$ & $1.970(14)$ & $1.958(3)$ & $1.953(4)$ \\
\hline M-S1 & $2.2967(6)$ & $2.2896(9)$ & $2.287(3)$ & $2.2926(9)$ & $2.2958(8)$ \\
\hline M-S2 & $2.2991(6)$ & $2.2889(11)$ & $2.281(3)$ & $2.2901(10)$ & \\
\hline M-Cl1 & $2.4070(6)$ & $2.3969(8)$ & $2.405(3)$ & $2.3989(8)$ & $2.3616(13)$ \\
\hline S1-C7 & $1.717(2)$ & $1.720(3)$ & $1.682(13)$ & $1.713(3)$ & $1.704(3)$ \\
\hline $\mathrm{S} 2-\mathrm{C} 15$ & $1.712(2)$ & $1.707(3)$ & $1.688(15)$ & $1.707(3)$ & \\
\hline $\mathrm{N} 1-\mathrm{C} 7$ & $1.311(3)$ & $1.321(5)$ & $1.301(15)$ & $1.317(5)$ & $1.318(4)$ \\
\hline N2-C15 & $1.314(3)$ & $1.313(5)$ & $1.338(18)$ & $1.312(5)$ & \\
\hline Cl1-M-C1 & $175.74(7)$ & $176.16(10)$ & $177.8(3)$ & $174.22(9)$ & 180 \\
\hline S1-M-S2 & $170.96(2)$ & $170.92(3)$ & $171.46(13)$ & $170.82(2)$ & $171.13(3)$ \\
\hline $\mathrm{H} 1 \cdots \mathrm{O} 1$ & 2.00 & 1.96 & 1.98 & 1.99 & 2.13 \\
\hline $\mathrm{H} 2 \cdots \mathrm{Cl} 1$ & 2.55 & 2.33 & 2.31 & 2.32 & \\
\hline
\end{tabular}

${ }^{\mathrm{a}}$ From reference [4] 


\section{Table 2}

Crystal Data and Details of Structure Refinement

\begin{tabular}{|c|c|c|c|c|}
\hline & $\mathbf{1} \cdot \mathrm{DMF}_{\mathrm{L}}$ & $\mathbf{1} \cdot \mathrm{DMF}_{\mathrm{Z}}$ & 1.DMAc & 1.2DMSO \\
\hline Chemical formula & $\begin{array}{l}\mathrm{C}_{22} \mathrm{H}_{19} \mathrm{~N}_{2} \mathrm{~S}_{2} \mathrm{PdCl} \cdot \\
\mathrm{C}_{3} \mathrm{H}_{7} \mathrm{NO}\end{array}$ & $\begin{array}{l}\mathrm{C}_{22} \mathrm{H}_{19} \mathrm{~N}_{2} \mathrm{~S}_{2} \mathrm{PdCl} \cdot \\
\mathrm{C}_{3} \mathrm{H}_{7} \mathrm{NO}\end{array}$ & $\begin{array}{l}\mathrm{C}_{22} \mathrm{H}_{19} \mathrm{~N}_{2} \mathrm{~S}_{2} \mathrm{PdCl} \cdot \\
\mathrm{C}_{4} \mathrm{H}_{9} \mathrm{NO}\end{array}$ & $\begin{array}{l}\mathrm{C}_{22} \mathrm{H}_{19} \mathrm{~N}_{2} \mathrm{~S}_{2} \mathrm{PdCl} \cdot \\
\mathrm{C}_{4} \mathrm{H}_{12} \mathrm{O}_{2} \mathrm{~S}_{2}\end{array}$ \\
\hline Formula weight & 590.47 & 590.47 & 604.50 & 673.64 \\
\hline Crystal system & monoclinic & monoclinic & monoclinic & orthorhombic \\
\hline Space group & $\mathrm{P} 2{ }_{1} / \mathrm{n}($ No 14$)$ & $\mathrm{P} 2_{1}(\mathrm{No} 4)$ & $\mathrm{P} 2_{1}(\mathrm{No} 4)$ & Pbcn (No 60) \\
\hline$a, \AA$ & $9.1001(3)$ & $9.3827(3)$ & 9.7192 & $28.6445(12)$ \\
\hline$b, \AA$ & $18.7316(6)$ & $11.3525(5)$ & $11.9849(6)$ & $10.6281(5)$ \\
\hline$c, \AA$ & $14.6434(5)$ & $12.4367(4)$ & $11.9672(5)$ & $9.3560(4)$ \\
\hline$\beta$, deg & $96.9912(10)$ & $108.8136(10)$ & $110.4477(12)$ & \\
\hline$V, \AA^{3}$ & $2477.55(14)$ & $1253.94(8)$ & $1306.15(9)$ & $2848.3(2)$ \\
\hline $\mathrm{Z}$ & 4 & 2 & 2 & 4 \\
\hline$\mu, \mathrm{cm}^{-1}$ & 10.493 & 10.366 & 9.971 & 10.659 \\
\hline$F(000)$ & 1200 & 600 & 616 & 1376 \\
\hline$D_{\text {calcd }}, \mathrm{g} \mathrm{cm}^{-3}$ & 1.583 & 1.564 & 1.537 & 1.571 \\
\hline Crystal size, $\mathrm{mm}$ & $0.20 \times 0.15 \times 0.10$ & $0.20 \times 0.20 \times 0.10$ & $0.50 \times 0.30 \times 0.10$ & $0.40 \times 0.15 \times 0.15$ \\
\hline Exposure rate sec. $/^{\circ}$ & 60.0 & 60.0 & 60.0 & 60.0 \\
\hline No. of data & 22834 & 12280 & 12569 & 25820 \\
\hline No. of unique data & 5595 & 5627 & 5770 & 3253 \\
\hline No. of variables & 311 & 281 & 316 & 170 \\
\hline$R(I>2 \sigma(I))$ & 0.0339 & 0.0299 & 0.0345 & 0.0421 \\
\hline$R$ (All reflections) & 0.0437 & 0.0351 & 0.0355 & 0.0594 \\
\hline$R_{\mathrm{W}}($ All reflections $)$ & 0.0798 & 0.0731 & 0.0891 & 0.1055 \\
\hline GOF & 1.044 & 1.109 & 1.071 & 1.038 \\
\hline
\end{tabular}


<smiles>S=C(NCc1ccccc1)c1cccc2c1[P+](Cl)(Cl)[SH]=C2NCc1ccccc1</smiles>

Crystallization from DMSO
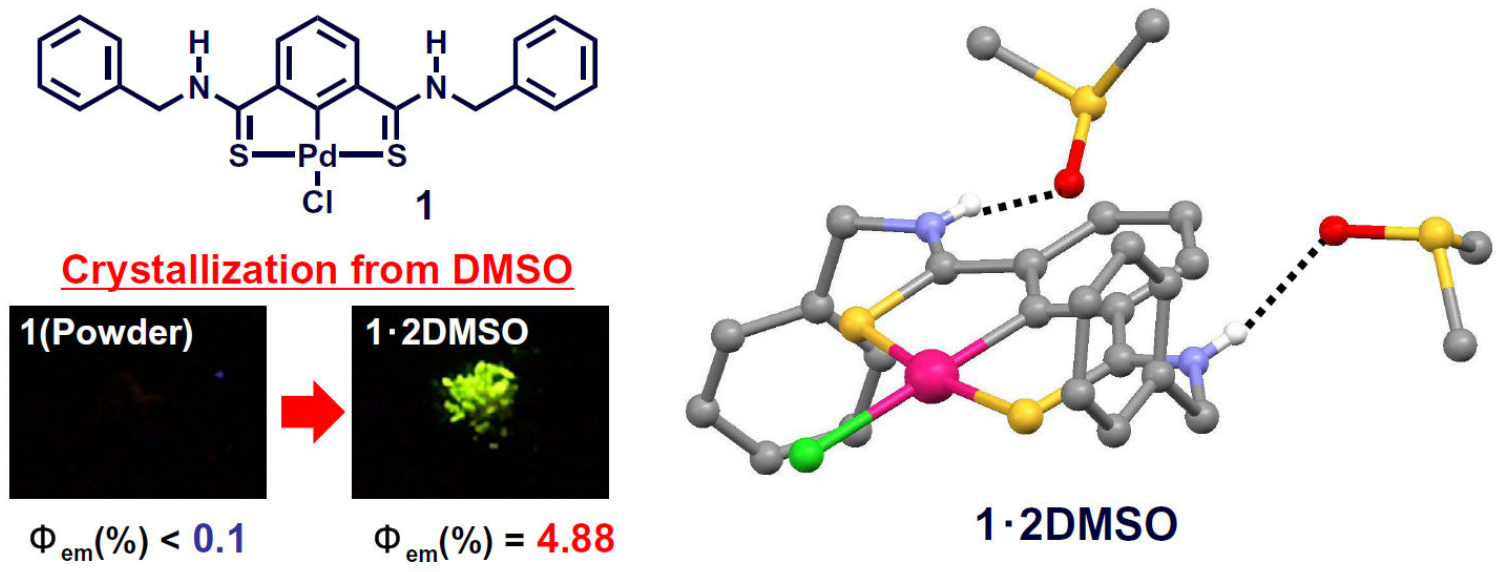